\title{
High radar-backscatter regions on Antarctic sea-ice and their relation to sea-ice and snow properties and meteorological conditions
}

\author{
SASCHA WILLMES*†, CHRISTIAN HAAS $\$ \S$ and MARCEL NICOLAUS $\ddagger$ I \\ $\dagger$ University of Trier, Department of Environmental Meteorology, Trier, Germany \\ tAlfred Wegener Institute for Polar and Marine Research, Bremerhaven, Germany \\ $\S$ Department of Earth and Atmospheric Sciences, Edmonton, Canada \\ IINorwegian Polar Institute, Tromsø, Norway
}

(Received 10 December 2008; in final form 9 March 2010)

\begin{abstract}
The temporal and spatial variability of sea-ice radar signatures in the Southern Ocean during late winter, spring and early summer from QuikSCAT data is presented. We observe a circumpolar and broad band of sea-ice close to the marginal ice zone that is characterized by very high radar backscatter. This feature is explained through detailed in situ observations of snow and sea-ice properties as well as in relation to meteorological conditions, which were derived from US National Center for Environmental Prediction (NCEP)/National Center for Atmospheric Research (NCAR) reanalysis data. Our results indicate that high backscatter regions are caused by metamorphous snow, which forms through re-freezing after short-term melt events. This process is connected with the episodic passes of low-pressure systems entraining warmer air from the north. South of the Antarctic Circumpolar Trough, sea-ice is not affected by this influence and shows spatially homogenous microwave signatures with low backscatter.
\end{abstract}

\section{Introduction}

Sea-ice extent in the Southern Ocean experiences a large interannual and seasonal variability (Zwally et al. 1983, Comiso and Gordon 1998). In the Weddell Sea in particular, winter pack ice extends further north than anywhere else around Antarctica and, in the western part of the Weddell Sea, the largest fraction of perennial ice can be found (Gloersen et al. 1992, Worby et al. 2008). Snow depth distribution is highly variable both spatially and temporally with deep snow $(>20 \mathrm{~cm})$ in the northwestern Weddell, Amundsen and Bellingshausen Seas, and thin snow $(<20 \mathrm{~cm})$ in the Indian Ocean and Western Pacific sectors (Massom et al. 2001, Markus and Cavalieri 2006). In regions with thick snow, surface flooding and freezing of slush at the snow-ice interface are frequently observed. The resulting flood-freeze cycles (Fritsen et al. 1998) lead to the formation of snow-ice, which can significantly contribute to the total sea-ice volume (Jeffries et al. 1997, Maksym and Markus 2008). Another important process for the Antarctic sea-ice mass balance is the formation of superimposed ice (Jeffries et al. 1994, Eicken 1998, Haas et al. 2001). This results from repeated freeze-thaw cycles (Colbeck 1997), which play an important role in snow metamorphism in the Antarctic (Massom et al. 2001, Willmes et al. 2006). Differences

*Corresponding author. Email: willmes@uni-trier.de 
in the evolution of first- and second-year snow covers in the Weddell Sea were presented by Nicolaus et al. (2009).

Active microwave remote sensing offers insight into large-scale changes of snow and ice properties. For example, Barber and Thomas (1998) used C-band radar measurements from the Arctic to show that a cloud-induced temperature effect on brine volume is responsible for an observed increase in surface scattering. Other studies in the Arctic explore backscatter variations, with respect to snowmelt and sea-ice mapping (Nghiem and Bertoia 2001, Steffen et al. 2004, Howell et al. 2006). Langlois et al. (2008), have shown for the Arctic that snow thermo-physical properties and hence dielectric features of the snow cover change significantly in the case of a low-pressure disturbance over sea-ice.

In addition, studies of sea-ice radar backscatter $\left(\sigma^{0}\right)$ of sea-ice regions in the Southern Ocean partially show different seasonal cycles with increasing backscatter during summer (Drinkwater and Liu 2000, Haas 2001). Willmes et al. (2009) showed that the observed backscatter increase is accompanied by a significant decrease in microwave brightness temperature and that both of these features are caused by snow metamorphosis in consequence of pronounced freeze-thaw cycles and the absence of persistent snowmelt.

A very significant, yet unexplained, feature regularly observed on Antarctic sea-ice is the occurrence of areas with very high sea-ice $\sigma^{0}$ close to the ice edge. Temporally limited events of strong $\sigma^{0}$ increases were found by Voss (2002) in the Ross Sea; however, no coincident field data were available for this study. Recently, two scientific cruises of the German ice breaker $R V$ Polarstern offered the opportunity to collect detailed data of physical snow and sea-ice properties in the high-backscatter regions. During the Ice Station Polarstern drift station (ISPOL; Hellmer et al. 2006, 2008) and the Winter Weddell Outflow Study (WWOS), ice and snow as well as meteorological data were collected along two transects through the northern and western Weddell Sea in November/December 2004 and from September to October 2006, respectively. Both cruises aimed to perform interdisciplinary measurements of processes at the ocean-seaice-atmosphere interface during the transition from late winter to early summer.

In this article, we present $\mathrm{Ku}$-band radar signatures and field measurements obtained during the transects of ISPOL and WWOS, as well as the long-term seaice backscatter variability in the Southern Ocean with the following main objective: to examine the causes for frequently observed rapid $\sigma^{0}$ fluctuations and the resulting occurrence of high radar-backscatter regions on Antarctic sea-ice. The seasonal evolution of $\sigma^{0}$ during spring and early summer is studied in comparison with in situ measurements of snow and sea-ice properties, as well as with the analysis of atmospheric forcing data from US National Center for Environmental Prediction (NCEP)/ National Center for Atmospheric Research (NCAR) meteorological reanalysis.

\section{Data}

Radar backscatter was obtained from daily gridded QuikSCAT Ku-band (13.4 GHz, vertical polarization) sea-ice $\sigma^{0}$ maps with water mask from the French Research Institute for Exploitation of the Sea. QuikSCAT backscatter data are resampled to a polar stereographic grid of $25 \times 25 \mathrm{~km}$ and available for the period from 1999 to 2009 (Ezraty and Piolle 2001). Daily near-surface temperature $\left(T_{\text {air }}\right)$, surface-wind and sealevel pressure (SLP) reanalysis fields were obtained from the US National Center for Environmental Prediction (NCEP/NCAR; Kistler et al. 2001) at the National 
Oceanic and Atmospheric Administration's (NOAA) Climate Diagnostics Center. Data were gridded and resampled to the QuikSCAT south polar grid. The occurrence of freeze-thaw days (FTD) in the area of investigation was derived from four-timesdaily fields of $T_{\text {air }}$, assigning an FTD when the four daily values included at least one value below and one above $0^{\circ} \mathrm{C}$.

To estimate the influence of sea-ice concentration on gridded radar backscatter, we used the Bootstrap Sea Ice Concentrations data set (Comiso 1999), distributed by the US National Snow and Ice Data Center. In addition to meteorological reanalysis data, we used $T_{\text {air }}$ from the meteorological mast of $R V$ Polarstern, which is automatically recorded together with the ship's position.

Snow and ice properties were measured on a daily basis along the ISPOL and WWOS transects through the Weddell Sea (figure 1). Floes were selected to be as representative as possible for the ice conditions around the ship. Regular ice observations (every $3 \mathrm{~h}$ ) from the ship's bridge supported the choice of the floes, which were then reached by helicopter while the vessel continued steaming. On each floe, a snow pit was dug on level ice to measure vertical profiles of temperature, wetness and density, and to describe snow stratigraphy (layer thickness, grain size, grain shape,
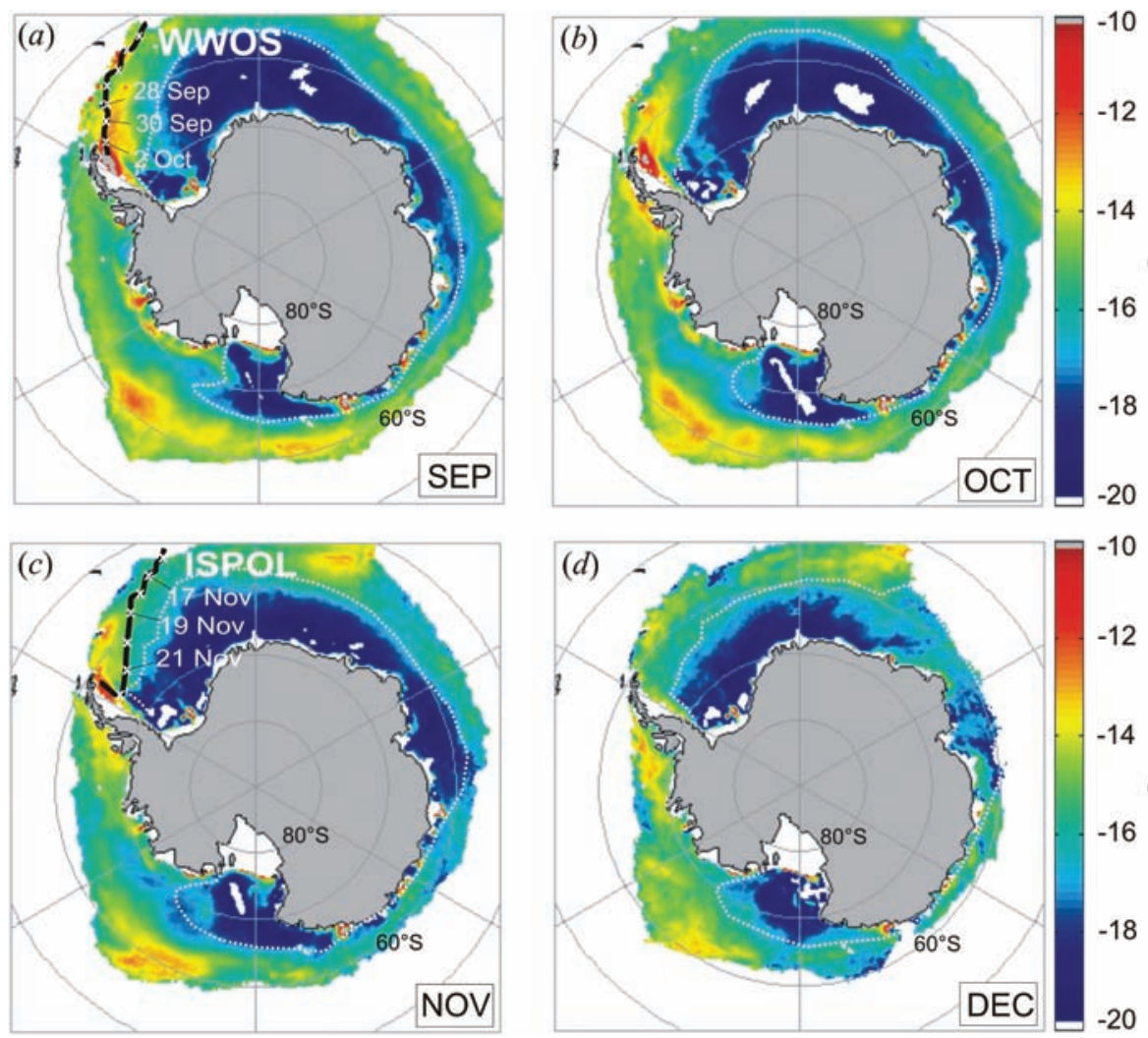

Figure 1. Monthly averages of $K u$-band sea-ice backscatter from QuikSCAT for the months of September $(a)$, October $(b)$, November $(c)$ and December $(d)$ in the period of 1999-2006. Cruise transects and selected positions of ISPOL (November 2004) and WWOS (September 2006) are plotted in the month of their main passage. A tentative identification of the transition from high to low backscatter regions is indicated by white dotted lines. 
hardness). Snow temperature was measured with a handheld Pt-1000 thermometer. Detailed results of additional snow properties like density and wetness, particularly during the later drift phase of the ISPOL expedition, can be found in Nicolaus et al. (2009). At each site, an ice core was drilled to measure vertical profiles of ice temperature and salinity, and to determine sea-ice texture. All ice cores were processed in a freezer laboratory on board by means of thin and thick section analysis (Lange and Eicken 1991).

\section{Results}

Multiyear average sea-ice Ku-band backscatter $\sigma^{0}$ as observed by QuikSCAT from 1999 to 2006 is presented in figure 1 for each month from September to December. The cruise transects of the ISPOL and WWOS expeditions are plotted in the month of their main passage, which means September for WWOS and November for ISPOL. There is a strong meridional gradient in the monthly averages of QuikSCAT $\sigma^{0}$ with decreasing values towards higher southern latitudes. A very sharp transition of $\sigma^{0}$ from larger than $-15 \mathrm{~dB}$ to values of $-20 \mathrm{~dB}$ divides sea-ice north of approximately $60^{\circ} \mathrm{S}$ from ice areas in higher latitudes. In the western Weddell, Amundsen and Bellingshausen Seas, high- $\sigma^{0}$ areas extend further south. The highest $\sigma^{0}$ values of $-10 \mathrm{~dB}$ are found east of the Antarctic Peninsula. Maximum values are decreasing from September to December. In general, the monthly $\sigma^{0}$ contrast over the entire sea-ice area is reduced from a range of $12 \mathrm{~dB}$ in September to $7 \mathrm{~dB}$ in December. This is mainly due to a decrease in maximum $\sigma^{0}$ from approximately -8 to $-13 \mathrm{~dB}$. Both ISPOL and WWOS transects are placed in the band of sea-ice that is characterized by high average $\sigma^{0}(>-15 \mathrm{~dB})$, subsequently referred to as high-backscatter regions (HBR).

On the transects from northeast to southwest, sea-ice texture and snow properties revealed a mixture of first- and second-year sea-ice covered by snow with highly variable thicknesses and different stages of metamorphism to be characteristic for HBR (figures 2 and 3). Snow stratigraphies were very heterogeneous along both transects, such that no regional trend could be observed. However, snow layering was characterized by alternating layers of soft to moderately hard slabs and icy layers (including melt clusters and coarse grained snow). Many of the sampled snow covers included prominent ice layers, indicating that the snow had already undergone thaw-freeze events before sampling, either recently or during the previous summer, as is typical for most second-year ice.

During ISPOL (November, figure $3 b$ ), snow was generally warmer and slightly thinner than during WWOS (September, figure $2 b$ ). However, snow surface temperature reached values close to $0^{\circ} \mathrm{C}$, that is, close to melting, even during some events in September (10, 26 and 28 September; figure $2 b$ ). The amplitude of (daily/spatial) surface temperature variations was significantly lower during ISPOL (approximately $-4-0^{\circ} \mathrm{C}$ ) than during WWOS (approximately $-15-0^{\circ} \mathrm{C}$ ). The higher number of ice layers in ISPOL snow is related to the later season and the fact that this snow had experienced more melt-freeze cycles than WWOS snow.

The shape and values of the presented salinity profiles as well as sea-ice textures and snow depths are indicative of a mixture of first-year (FYI) and second-year sea-ice (SYI), denoting an increase of the fraction of SYI towards the western Weddell Sea (figures $2 b$ and $3 b$ ). Mean and modal average snow thicknesses on the sampled floes, as derived from ruler stick measurements, also slightly increased while the ship was moving southwestwards, which confirms the results of Markus and Cavalieri (2006), 

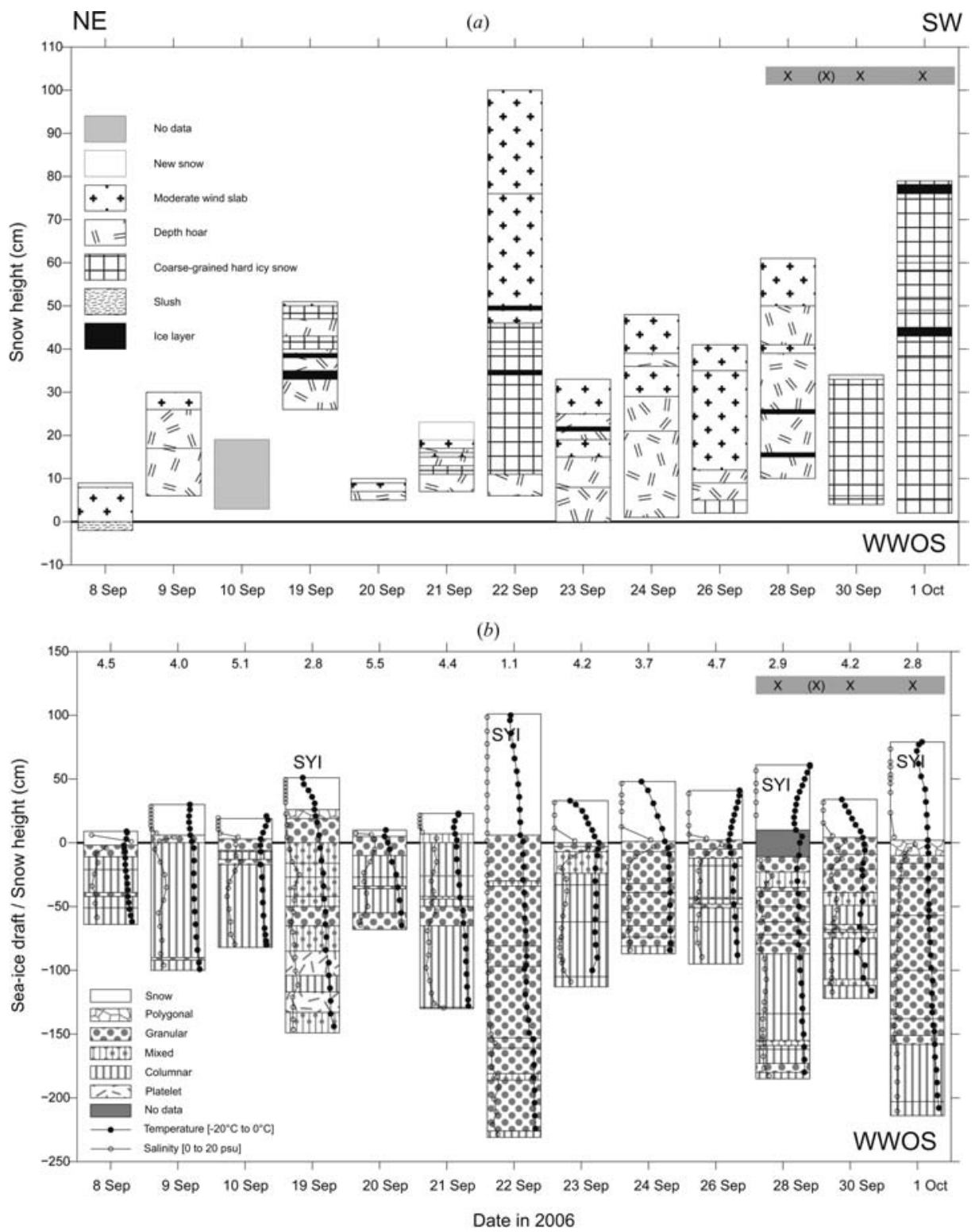

Figure 2. (a) Snow stratigraphy at all ice stations along the WWOS transect. (b) Sea-ice texture, temperature and salinity of all ice stations along the WWOS transect. Temperature and salinity are scaled within each single core texture, such that temperature ranges from $-20^{\circ} \mathrm{C}$ (left) to $0^{\circ} \mathrm{C}$ (right) and salinity from 0 PSU (left) to $20 \mathrm{PSU}$ (right). Horizontal lines separate stratigraphic units from distinct growth stages or rafting. Additionally, snow thickness, temperature and salinity are shown. A snow height of 0 refers to water level, such that all snow stratigraphies, sea-ice textures, salinities and temperatures are plotted considering freeboard. Note the gap of 8 days after 10 September in the time series. Numbers on top give mean salinity of the ice core. The grey bar with crosses on top denotes the dates shown in figure 5. Transect orientation from NE to SW is indicated on top. PSU (practical salinity units) is a dimensionless number derived from the conductivity ratio between the sample and the standard solution $(1 \mathrm{~kg}$ with $32.44 \mathrm{~g}$ potassium chloride at $15^{\circ} \mathrm{C}$ ) according to the Practical Salinity Scale. Based on this scale, a sample with conductivity equal to the standard solution has a PSU value of 35 . 
(a)

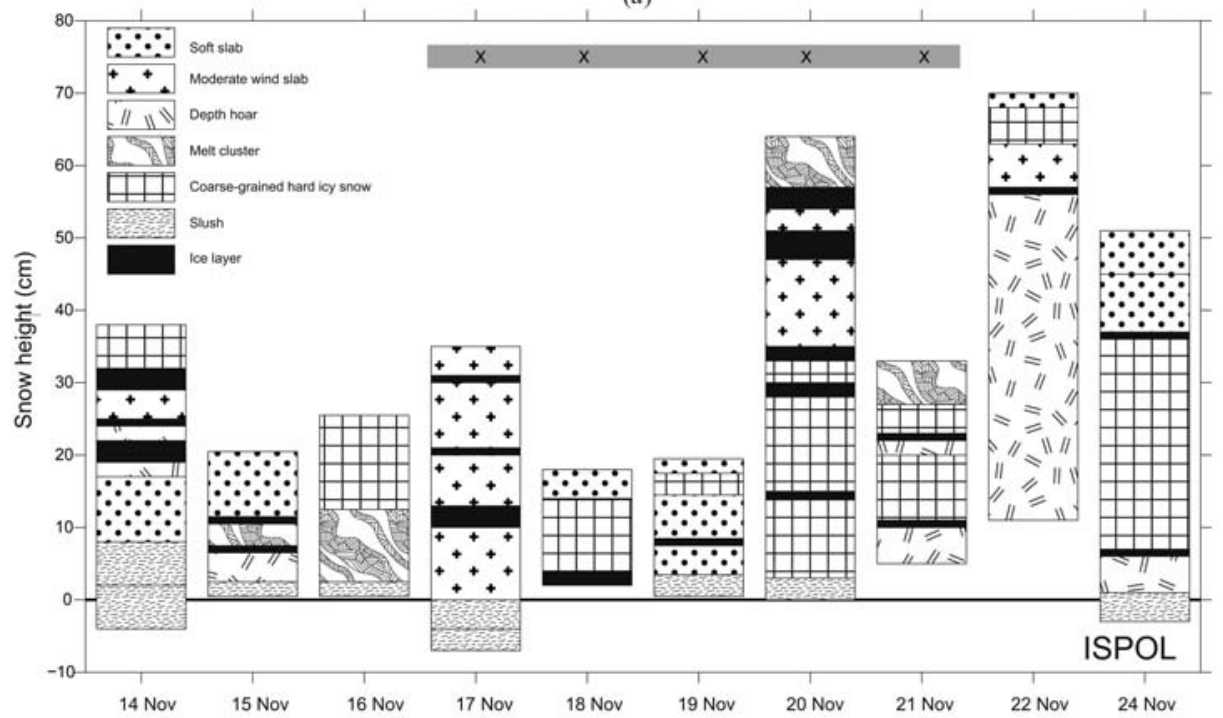

(b)

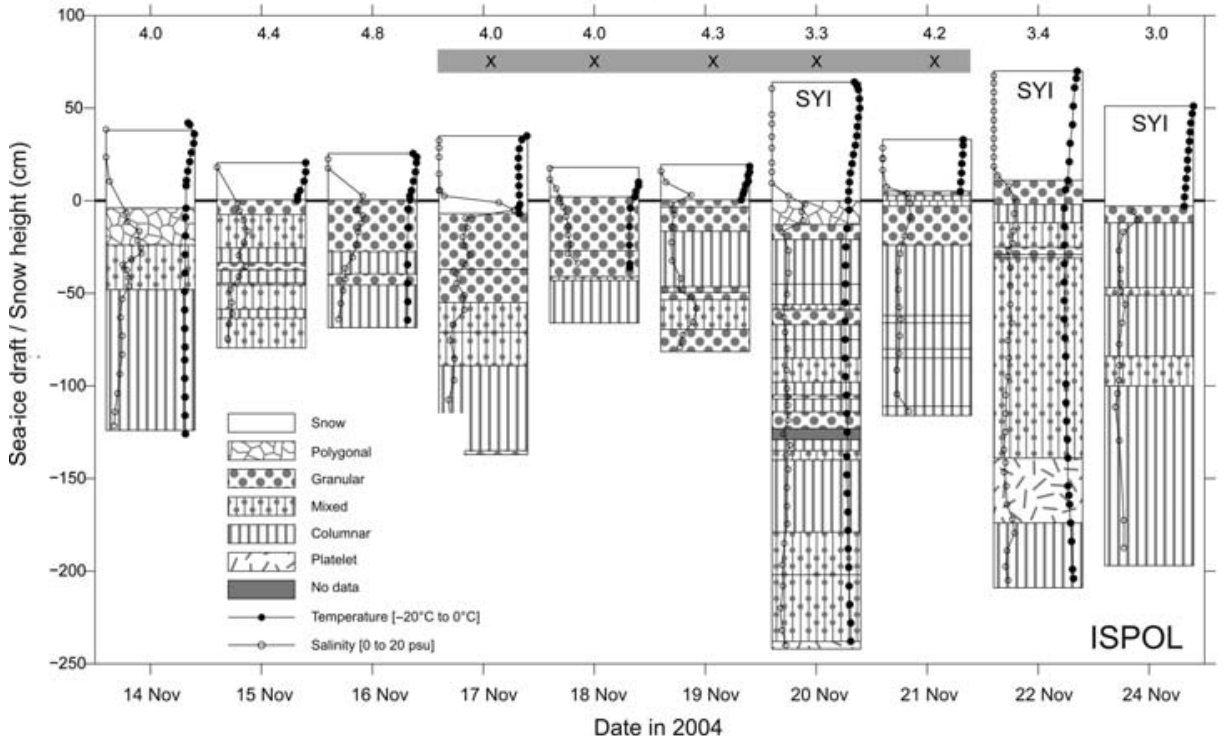

Figure 3. (a) Snow stratigraphy at all ice stations along the ISPOL transect. (b) Sea-ice texture, temperature and salinity of all ice stations along the ISPOL transect. Temperature and salinity are scaled within each single core texture, such that temperature ranges from $-20^{\circ} \mathrm{C}$ (left) to $0^{\circ} \mathrm{C}$ (right) and salinity from 0 PSU (left) to 20 PSU (right). Horizontal lines separate stratigraphic units from distinct growth stages or rafting. Additionally, snow thickness, temperature and salinity are shown. A snow height of 0 refers to water level, such that all snow stratigraphies, sea-ice textures, salinities and temperatures are plotted considering freeboard. Numbers on top give mean salinity of the ice core. The grey bar with crosses on top denotes the dates shown in figure 6 . Transect orientation from NE to SW is indicated on top. 
(a) - $T_{\text {air }}$ (5-minute values)

$\bullet T_{\text {air }}$ (daily averages)

$\diamond \diamond \diamond$ Backscatter (daily averages)

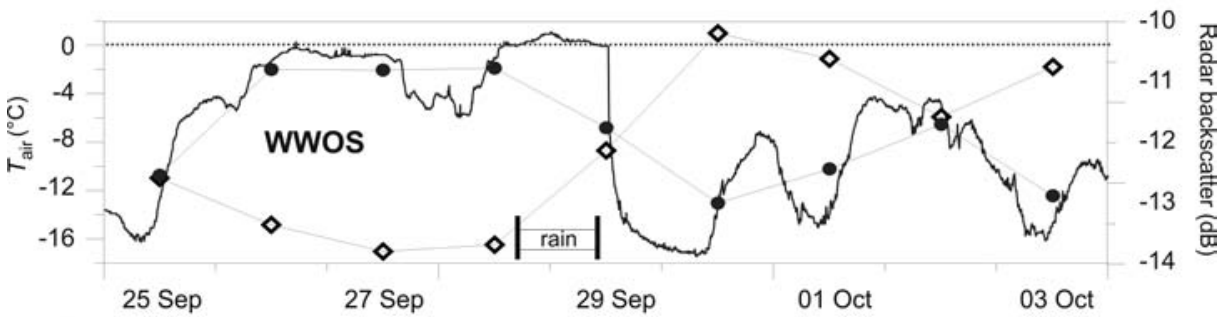

(b)

Date in 2006

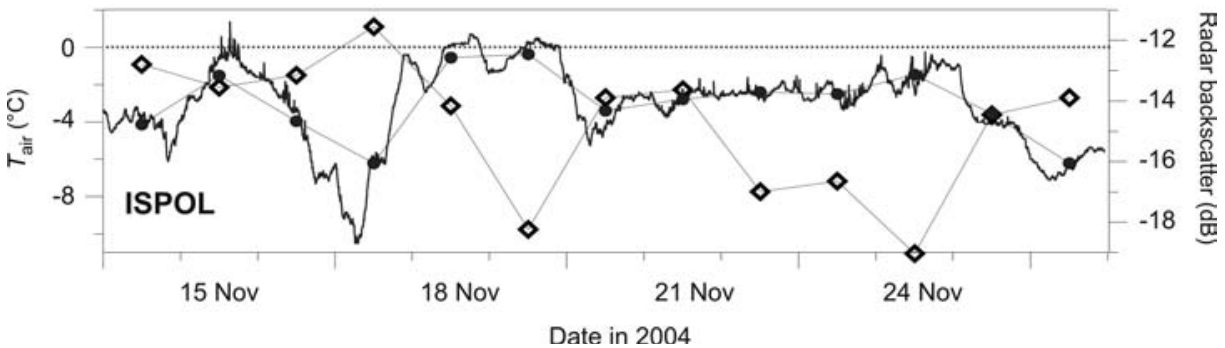

Figure 4. $\quad R V$ Polarstern of 5 min values of $T_{\text {air }}$ (black line), daily averages of $T_{\text {air }}$ (dots) at the position of $R V$ Polarstern at particular date (from onboard meteorological station) and daily averages of surface backscatter (diamonds) in the pixel containing the ship's position during the transects of WWOS $(a)$ and ISPOL $(b)$. Figures 5 and 6 show overviews of the regional changes of these parameters during the same periods.

who detected higher snow depths in the western Weddell Sea adjacent to the Antarctic Peninsula than in the northern Weddell Sea.

In figure 4 , the evolution of $\sigma^{0}$ at the pixel containing the ship's positions on the ISPOL and WWOS transects is compared with $T_{\text {air }}$ measured on the ship. The time series reveal that $\sigma^{0}$ is generally inversely correlated with $T_{\text {air }}$ during both transects such that lower air temperatures coincide with higher surface backscatter. The magnitude of daily mean $T_{\text {air }}$ changes does not seem to determine the magnitude of backscatter changes.

As gridded daily averages of radar backscatter are used, the effect of short-term cooling events on backscatter appears smoothed due to subsequent warming or vice versa. For example, a drop of daily averaged $T_{\text {air }}$ on 29 September 2006 (figure 4a) resulted in a remarkable maximum of $\sigma^{0}$ one day later, on 30 September. However, one can see from the $5 \mathrm{~min} T_{\text {air }}$ time series that the cooling took place in the middle of the day, such that warmer air in the first-half of 29 September probably still caused lower backscatter, which resulted in only moderately higher average daily backscatter. The fact that there was rain of up to $0.6 \mathrm{l} / \mathrm{h}$ during the first-half of 29 September probably significantly contributed to this observation.

With high ice concentrations $>80 \%$, the variability of $\sigma^{0}$ is mostly caused by variable underlying ice types like FYI and SYI, which are characterized by different roughness, salinity and average snow thickness, as well as snow wetness and metamorphism (Eppler et al. 1992, Onstott 1992). In the spring and early summer seasons, the latter is of special concern, as the formation of meltwater through snowmelt induces drastic changes in the observed $\sigma^{0}$ signals (Nghiem and Bertoia 2001, Haas 2001, Willmes et al. 2006, Bartsch et al. 2007). From the presented time series, we conclude that re-freezing of the seasonally warming snow cover causes irreversible 
snow structures (grain size increases, ice layers), leaving increased radar backscatter. Once this state of the surface is reached, only snow moistening events during warm air advection periods cause decreasing backscatter through radar wave attenuation in meltwater.
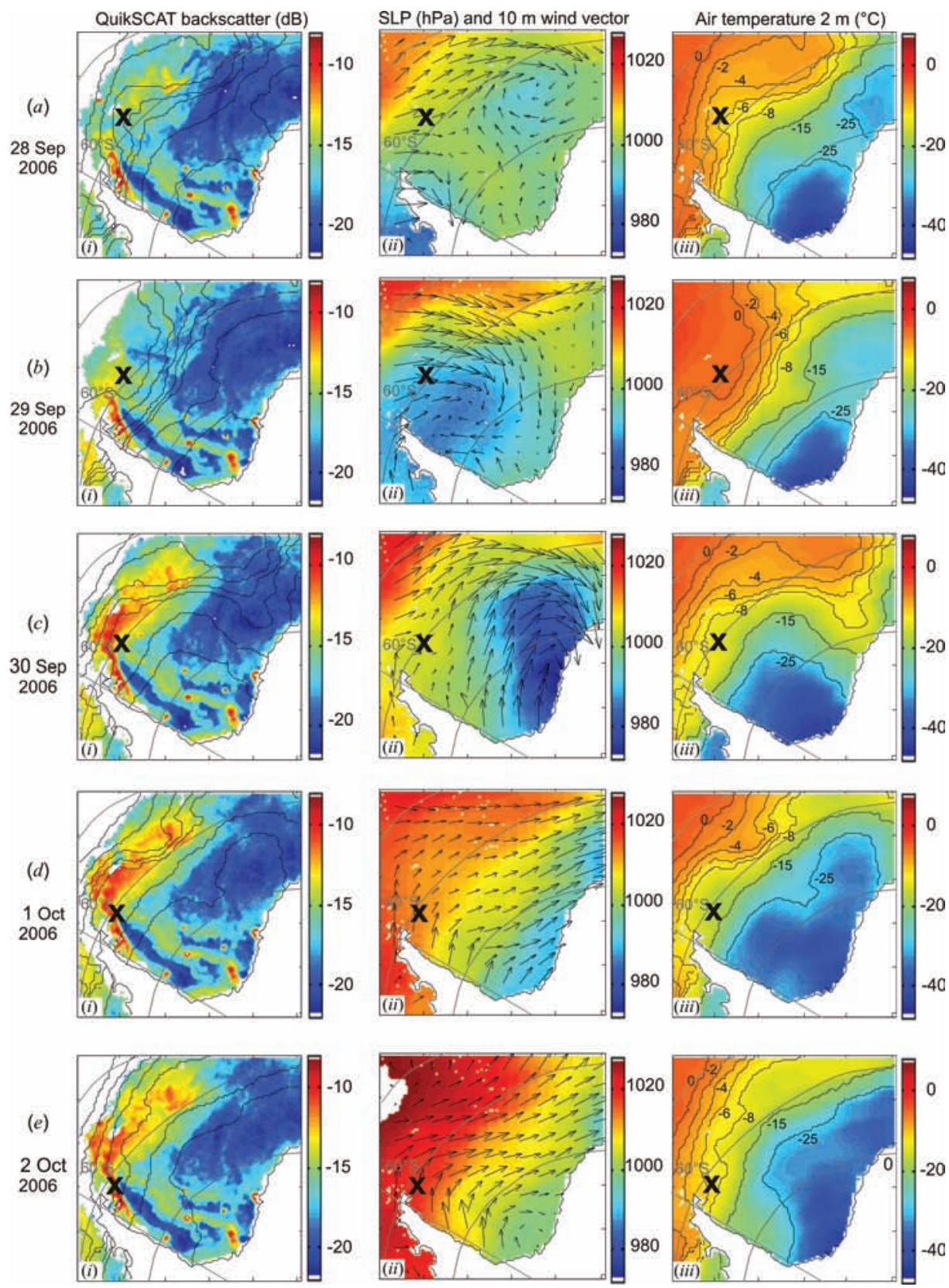

Figure 5. Sea-ice backscatter ( $i$ ), $T_{\text {air }}$ isotherms from NCEP/NCAR data, SLP and $10 \mathrm{~m}$ wind vector (ii) and near-surface air temperature with isotherms (iii) in the Weddell Sea on five consecutive days during the WWOS transect presented in figure 4. Black crosses indicate the position of $R V$ Polarstern on the respective date. 

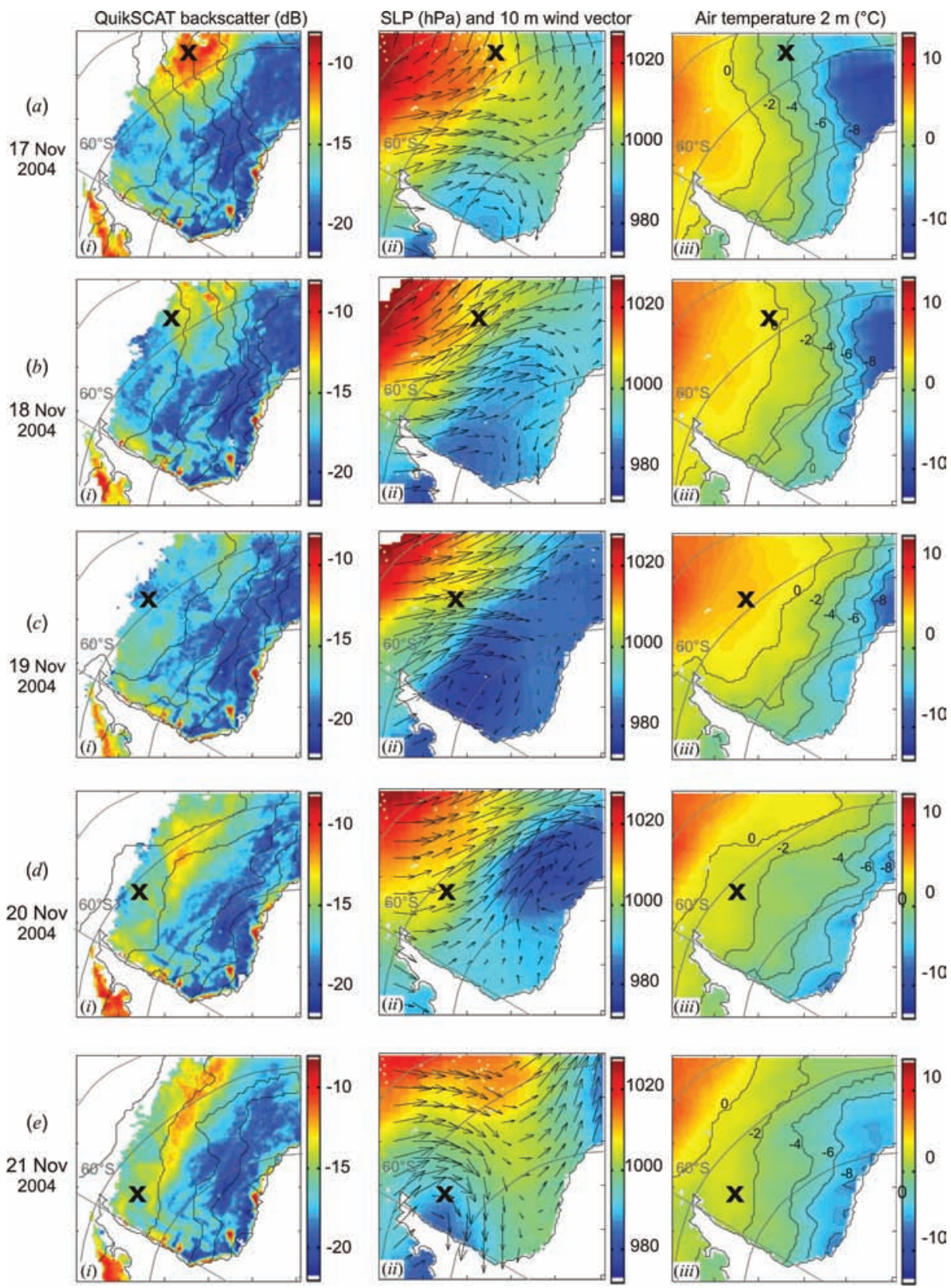

Figure 6. Sea-ice backscatter ( $i$ ), $T_{\text {air }}$ isotherms from NCEP data, SLP and $10 \mathrm{~m}$ wind vector (ii) and near-surface air temperature with isotherms (iii) in the Weddell Sea on five consecutive days during the ISPOL transect presented in figure 4. Black crosses indicate the position of $R V$ Polarstern on the respective date.

Figures 5 and 6 show the spatial and temporal relationship between backscatter changes and the passage of warm air masses for the two examples in figure 4 . The evolution of $\sigma^{0}$, SLP, $10 \mathrm{~m}$ wind vectors and near-surface $T_{\text {air }}$ in the Weddell Sea are shown during five consecutive days spanning the periods of strong backscatter 
variations. On 28 September 2006, one can recognize HBR in the northwestern Weddell Sea north of approximately $60^{\circ} \mathrm{S}$ (figure $5 a$ ). The latter represents most likely rather levelled FYI with a comparably thin snow cover that formed in the coastal polynyas of the southern Weddell Sea. On 29 September, SLP (figure 5b(ii)) shows that a low-pressure system has reached the western Weddell Sea, advecting warm air from the north and moving the $0^{\circ} \mathrm{C}$ isotherm (figure $5 b(i i i)$ ) southwards. Coincidently, $\sigma^{0}$ in HBR is decreasing (figure $5 b(i)$ ). One day later, however, a drastic increase of $\sigma^{0}$ values in HBR can observed. This goes along with significantly colder air with a strong northward shift of the $T_{\text {air }}$ isotherms (figure $5 c(i i i)$ ). The high $\sigma^{0}$ continues on 1 and 2 October (figures $5 d$ and $5 e$ ), while no significant change of air masses occurred over the observed area. A narrow band of sea-ice east of the Antarctic Peninsula shows persistently high $\sigma^{0}$ values of approximately $-10 \mathrm{~dB}$ throughout the presented period of 5 days.

During ISPOL a comparable event was observed. On 17 November 2004 (figure $6 a(i)$ ), high $\sigma^{0}$ prevailed in the northeastern Weddell Sea, south of the $0^{\circ} \mathrm{C}$ isotherm (figure $6 a(i i i)$ ). The band of FYI parallel to the Antarctic peninsula is much less pronounced as compared with that of September 2006 (figures 1 and 5). On 18 November, $\sigma^{0}$ in HBR decreased by about $5 \mathrm{~dB}$ whilst a low-pressure system was approaching from the West and the $T_{\text {air }}$ isotherms were shifted southwards (figure $6 b(i-i i i)$ ). This change was enhanced on 19 November, when the low was centred over the Weddell Sea. One day later, however, $\sigma^{0}$ values in HBR increased again when $T_{\text {air }}$ was strongly decreasing in the same area. This continued on 21 November, resulting in a large east-west extending band of high $\sigma^{0}$ values, almost parallel to the $T_{\text {air }}$ isotherms in the northern Weddell Sea.

From the presented results, we conclude that the sharp $\sigma^{0}$ transition between the northern and southern ice zones as shown in figure 1 can be explained by the formation of metamorphous snow under the influence of changing air masses in the proximity of a region that is characterized by a high frequency of extratropical cyclones and referred to as the Antarctic Circumpolar Trough (Simmonds and Keay 2000, Venegas and Drinkwater 2001). Average sea-ice $\sigma^{0}$ for the 4 months from September to December (1999-2006) is shown in figure 7 in comparison with a map of the average monthly frequency of FTD. Between September and December, FTD over sea-ice are mostly occurring in the northern Weddell Sea, west of the

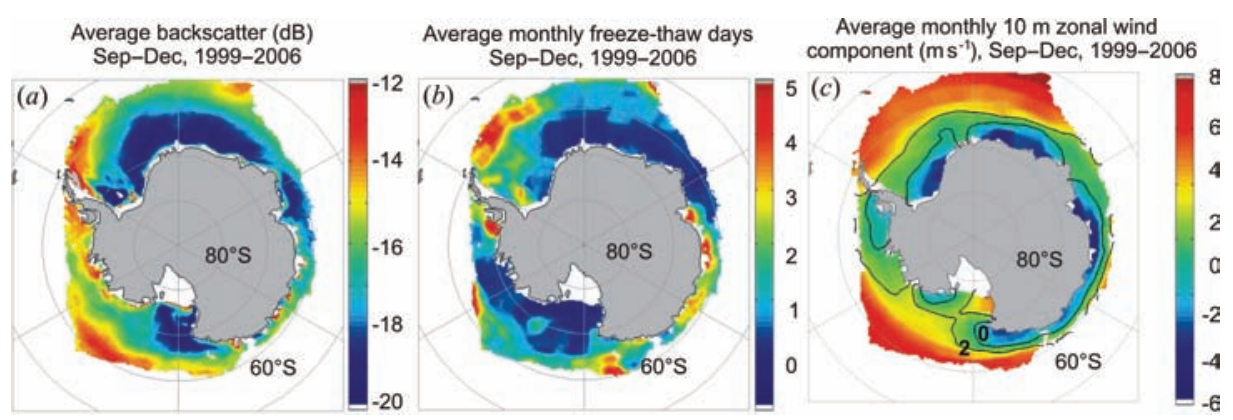

Figure 7. Average of sea-ice backscatter (a), average number of freeze-thaw days (FTD) per month from NCEP $T_{\text {air }}$ data $(b)$ and average zonal $10 \mathrm{~m}$ wind component from NCEP reanalysis $(c)$ for sea-ice area with sea-ice concentration larger than $80 \%$ in the months of September to December in the period from 1999 to 2006. 
Antarctic Peninsula and along the coast of the Western Pacific Sector (figure $7 b$ ). Regions with low average sea-ice $\sigma^{0}$ (figure $7 a$ ) are predominantly found where the frequency of FTD is low. This, together with the mean zonal component of the $10 \mathrm{~m}$ wind vectors (figure $7 c$ ), indicates that the transition from HBR to the southern Weddell Sea is influenced by the position of the Antarctic Circumpolar Trough, where warm and moist air masses north of approximately $65^{\circ} \mathrm{S}$ are separated by cold easterly winds in the south.

\section{Discussion}

The correlation of atmospheric forcing with sea-ice $\sigma^{0}$ is explained as follows: the approach of extra-tropical cyclones causes the entrainment of warm air into the Antarctic Circumpolar Trough, which occasionally might raise $T_{\text {air }}$ over $0^{\circ} \mathrm{C}$ from late winter to summer. Such a short-term warming, superimposed on the radiatively driven diurnal cycle of snow skin temperature (Vihma et al. 2009), can be sufficient to trigger the formation of short-term snowmelt events. A subsequent decrease of $T_{\text {air }}$ in turn causes a re-freezing of melt water and/or water vapour within the snow pack and leaves high $\sigma^{0}$ signals as grain sizes have grown. Possible superimposed ice and ice lenses are formed and thus volume scattering is increased (Onstott 1992, Haas 2001, Nghiem and Bertoia 2001). The dominance of freeze-thaw cycles over the occurrence of persistent melting is also responsible for the slow decreases in microwave emissivity observed during the same time periods and in the same regions in the western Weddell Sea (Willmes et al. 2006), allowing the development of algorithms to detect the onset of thaw-freeze cycling in spring (Willmes et al. 2009).

Hence, HBR is special in terms of its typical $T_{\text {air }}$ variability from spring to early summer. Here, the temperature oscillates around $0^{\circ} \mathrm{C}$, whereas further south, melt events occur with a much lower frequency, which can be explained by generally low atmospheric energy input, because turbulent fluxes are predominantly from snow to air and compensate most of the energy entry through short-wave radiation (e.g. Nicolaus et al 2009, Vihma et al. 2009). Snow ablation is dominated by evaporation while melt is of minor importance (Andreas and Ackley 1982, Nicolaus et al. 2006).

A more detailed interdependency of average $\sigma^{0}$ and atmospheric forcing is shown by means of a contour scatter plot in figure 8 , with colour shades indicating the pixel density distribution. Averaged over the months of September to December, there is a cluster of $\sigma^{0}$ values which is positively correlated with the frequency of FTD. Already the first occurrence of freezing and thawing (up to two monthly FTD on average) often leads to an increase of backscatter from -19 to $-16 \mathrm{~dB}$. Looking at the months of September to December separately reveals that there is also another component in the correlation of the presented parameters. Only for $\sigma^{0}$ lower than approximately $-15 \mathrm{~dB}$ does an increase in FTD induce higher $\sigma^{0}$. For $\sigma^{0}$ higher than $-15 \mathrm{~dB}$, values decrease with increasing frequency of FTD. This is especially seen in the months of September, October and November. In December, the total $\sigma^{0}$ range is narrowed and the correlation with the occurrence of FTD is not significant, while the negative correlation above $-15 \mathrm{~dB}$ as seen in September, October and November is averaged out. This supports the observation that maximum values of the observed $\sigma^{0}$ are decreasing throughout spring (compare results and figure 1), and may be explained by a general increase of snow moisture as further discussed below.

Despite the qualitative correlations between the number of FTD and $\sigma^{0}$ shown in figure 8 , actual correlation coefficients are very low (approximately -0.13 for $>-15 \mathrm{~dB}$ 

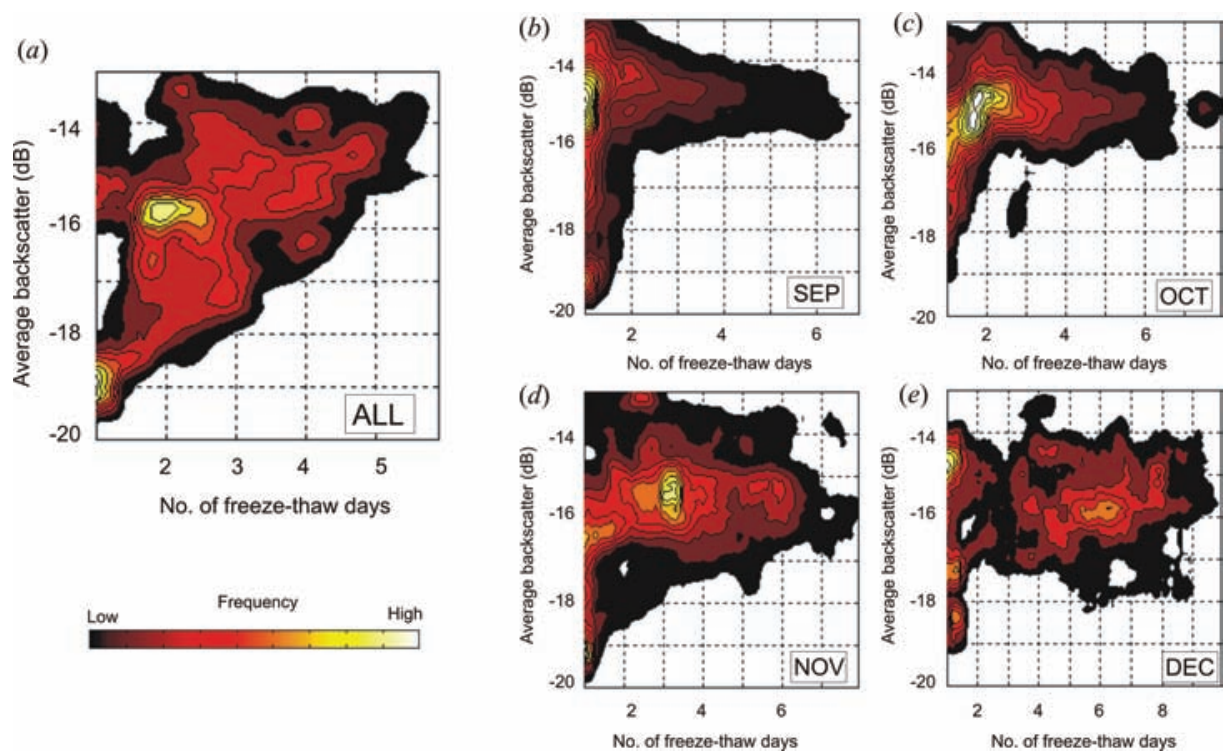

Figure 8. Contour scatter plots of number of FTD vs average backscatter for sea-ice in the Antarctic for the months of September to December, averaged for the period from 1999 to 2006 for sea-ice concentrations $>80 \%$.

and 0.3 for $<-15 \mathrm{~dB}$ ). This results from the fact that the total Antarctic sea-ice area has been included in the analysis, although it is clear that only the relatively small regions of the HBR contribute to a more significant correlation. However, these regions are not separable from one another in an objective way. The suggested threshold of $-15 \mathrm{~dB}$ was subjectively chosen to demarcate HBR from lower backscatter regions, which is justified by the systematically negative correlations above and positive correlations below this value.

Sea-ice Ku-band $\sigma^{0}$ seems to be strongly affected by the first occurrence of snow metamorphism after thawing and re-freezing. Additional FTD do not raise the surface $\sigma^{0}$ any further. Instead, if $\sigma^{0}$ was initially larger than approximately $-15 \mathrm{~dB}$ (i.e. due to highly metamorphous snow on SYI or large surface roughness), it decreases with an increasing frequency of FTD, during the seasonal evolution from early spring to summer. This might be explained by metamorphous, highly scattering snow masking out $\sigma^{0}$ contrasts that resulted from different ice types and is expressed in the scatter plot contours (figure 8) narrowing with an increase in FTD (September-November).

The main factors controlling sea-ice $\sigma^{0}$ are, amongst others, surface salinity, surface wetness and surface roughness (Onstott 1992, Drinkwater 1998, Haas 2001, Nghiem et al. 2001). The latter includes the effects of snow stratigraphy and snow grain sizes, which are both subject to significant changes during the spring and summer seasons due to temporary melting (e.g. Nghiem and Bertoia 2001). Strong snowmelt with significant wetting of the snow strongly attenuates radar waves and causes decreased $\sigma^{0}$ (Nghiem et al. 1998, 2001). This feature can be used to identify the onset of snowmelt (Drinkwater and Liu 2000, Steffen et al. 2004). In figures 5 and 6, we showed examples of how the passage of a low-pressure system caused such a melt event on sea-ice in the Antarctic and led to sudden decreases of surface $\sigma^{0}$. This 
decrease is very similar to what is found on Arctic multiyear sea-ice, when liquid water forms in the snow pack (Barber and Thomas 1998). However, on longer, seasonal timescales, repeated freeze-thaw cycles prevail on Antarctic sea-ice instead of strong and persistent melting (Willmes et al. 2009). This was shown to cause highly metamorphous snow and eventually superimposed ice, which in turn induces increasing $\sigma^{0}$ (Haas 2001, Willmes et al. 2006). The results presented here underline the strong influence of the prevailing atmospheric variability on surface properties and thus spatial and temporal sea-ice $\sigma^{0}$ variability. As shown in figures 5 and 6 , re-freezing of snow drastically increases $\sigma^{0}$. On average, regions affected by air temperatures oscillating around the freezing temperature of $0^{\circ} \mathrm{C}$ show comparably high average surface $\sigma^{0}$ due to metamorphous snow.

The increase of the dielectric constant at the snow basal layer due to the downward propagation of positive temperature signals has been reported to play a significant role in C-band microwave scattering of Arctic sea-ice (Barber and Thomas 1998). Barber and Thomas observed an increase of $\sigma^{0}$ as a consequence of increased temperatures at the snow-ice interface, which implies lower $\sigma^{0}$ when temperatures are decreasing again. In fact, this is opposite to what we describe here for sea-ice in the Antarctic. We observed a decrease of $\sigma^{0}$ when temperatures were rising and vice versa. This results from the fact that, in our region and period of interest, temperature variations are very often connected to freeze-thaw processes. Moreover, in the Southern Ocean, snow is generally deeper, which impedes the propagation of temperature waves down to the snow-ice interface where ice temperature and porosity would be affected. We show Ku-band data which have a smaller penetration depth than C-band data and are thus more sensitive to changes in the snow pack.

Considering average snow depths of approximately $35 \mathrm{~cm}$ on the transects, the $\sigma^{0}$ variations we observe occur on too short time scales to be induced by the effects of brine. We found coarse-grained snow and ice layers throughout both transects from the northern to the southwestern Weddell Sea (figures 2 and 3). This feature induces strong scattering, which has the potential to mask out the contribution of basal layers to the total backscatter (Nghiem et al. 2001). Nevertheless, brine-temperature changes in consequence of low-pressure disturbances as described by Langlois et al. (2008) for Arctic sea-ice will also affect the $\sigma^{0}$ in the Antarctic. However, we suppose this to play a role mainly in cold and dry snow during winter.

Detection and interpretation of high-backscatter regions are complicated by other ice properties affecting backscatter, in particular when the snow is still fresh and cold, and when its effect on backscatter is reduced. For example, SYI has generally higher backscatter than FYI, which is a result of snow metamorphism and superimposed ice formation during the previous summer and a generally higher geometric surface roughness. This is obvious in the region along the Antarctic Peninsula and the Larsen ice shelf, where drift convergence induces the formation of ridged and thick ice which is characterized by high $\sigma^{0}$ values (figures 5 and 6; Drinkwater 1998, Worby et al. 2008).

A mixture of FYI and SYI is very typical for this region (Haas et al. 2008). The SYI fraction contributes to very high observed $\sigma^{0}$ irrespective of recent thaw-freeze cycles. In between, a band of thin and rather smooth FYI is often advected northwards. The higher surface salinity and the generally more levelled surface of this FYI cause the distinct band of low $\sigma^{0}$. With the progress of seasons, the prevalence of diurnal freeze-thaw cycles (as shown for the western Weddell Sea by Willmes et al. 2006 and Willmes et al. 2009) induces metamorphous snow, which levels $\sigma^{0}$ out at values of -15 $\mathrm{dB}$ and obscures these regional differences. 

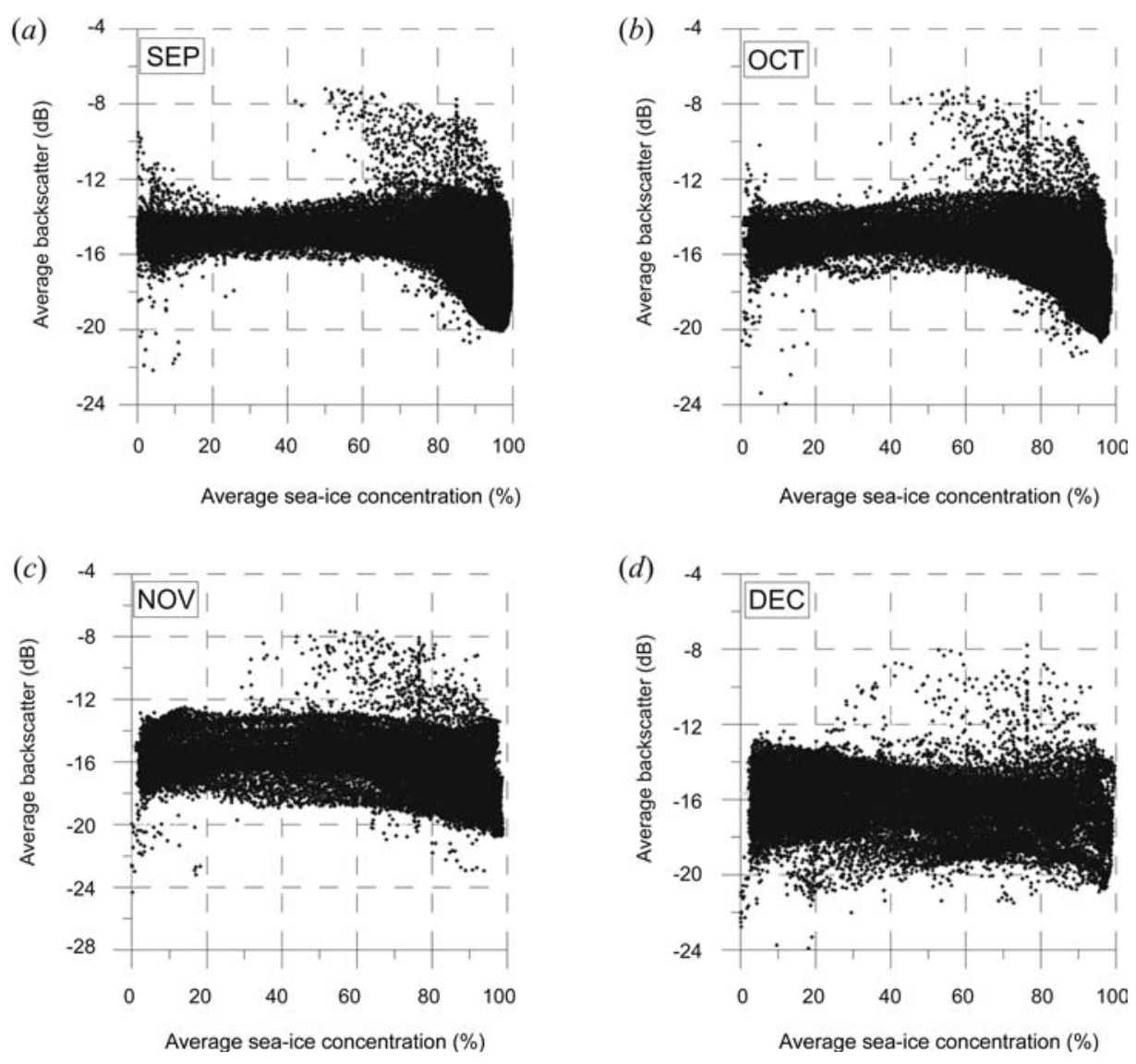

Figure 9. Scatter plots of sea-ice concentration versus average backscatter for sea-ice in the Antarctic for the months of September to December, averaged for the period from 1999 to 2006.

Another potential reason for the occurrence of HBR could be high fractions of open water and small floes and brash ice within a pixel area, which may cause misinterpretations of high sea-ice $\sigma^{0}$. Therefore, figure 9 gives an estimate of the influence of sea-ice concentration (SIC) on the presented $\sigma^{0}$ values. It can be seen that the analysed QuikSCAT data (Ezraty and Piolle 2001) do not reveal significantly higher values in areas of low sea-ice concentration.

In fact, the decrease in $\sigma^{0}$ with increasing SIC is revealed to be mostly due to average $\sigma^{0}$ being smaller than $-17 \mathrm{~dB}$ for SIC $>80 \%$. This results mainly from the southern sea-ice areas (compare figure 1), where SIC is high and the influence of warm air is small. From figure 9, we conclude that the presented HBR are not an effect of the spatial variability of SIC.

Our results indicate that snow metamorphism caused by diurnal and inter-diurnal freeze-thaw cycles is the dominant factor for the spatial $\sigma^{0}$ variability on sea-ice during spring and early summer months. As a result, ice type contrasts are masked out and maximum $\sigma^{0}$ decreases from September to December, which indicates that studies discriminating ice types through the use of scatterometers signatures (Voss et al. 2003) are limited to the presence of dry (or no) snow. 
With respect to snowmelt studies (Drinkwater and Liu 2000, Willmes et al. 2009) our results imply that, at least for the months of September to December, the duration of melting is very limited and restricted to areas temporarily affected by warm and moist air from north of the Antarctic Circumpolar Trough.

\section{Conclusions}

Sea-ice radar $\sigma^{0}$ from spring and early summer in the Southern Ocean was examined together with detailed field measurements of ice and snow properties and meteorological conditions. We found that a broad band of sea-ice south of the ice edge is characterized by large, short-term oscillations of $\sigma^{0}$, combined with very high average radar $\sigma^{0}$. These changes occur within a few days, and are negatively correlated with variations of $T_{\text {air }}$.

We explain this behaviour with the high frequency of low sea-level pressure disturbances advecting warm and moist air into the Antarctic Circumpolar Trough. The corresponding variability of $T_{\text {air }}$ induces strong snow metamorphism and thus increases surface radar backscatter during the following cooling periods and the accompanied re-freezing of the snow.

Our results reveal that high backscatter occurs with the first re-freeze event and does not increase much further with additional re-freezing events. Highest backscatter values in early spring are probably caused by rough and deformed SYI. Here, freeze-thaw cycles and the corresponding snow metamorphism rather cause decreases in backscatter. All in all, this results in a seasonal decrease of the spatial sea-ice backscatter contrast. The regions of FYI south of the high- $\sigma^{0}$ regions do not reveal significant seasonal changes in $\sigma^{0}$ before they disintegrate.

\section{Acknowledgements}

The authors are very grateful to two anonymous reviewers for their helpful and constructive comments. Moreover, we would like to thank the members of the ISPOL and WWOS expeditions for encouraging discussions and lending a helping hand during fieldwork, especially Anja Nicolaus, Takenobu Toyota and Zhijun Li. Scatterometer data were provided by the French Research Institute for Exploitation of the Sea, sea-ice concentrations by the US National Snow and Ice Data Center and meteorological reanalysis data by NCEP/NCAR. This study was partly funded by the German Research Foundation (DFG) under contract BA 2060/2-2 and HA 2724/4-2.

\section{References}

Andreas, E.L. and Ackley, S.F., 1982, On the differences in ablation seasons of Arctic and Antarctic sea ice. Journal of Atmospheric Science, 39, pp. 440-447.

Barber, D. and Thomas, A., 1998, The influence of cloud cover on the radiation budget, physical properties, and microwave scattering coefficient $\left(\sigma^{0}\right)$ of first-year and multiyear sea ice. IEEE Transactions on Geoscience and Remote Sensing, 36, pp. 38-50.

Bartsch, A., Kidd, R.A., Wagner, W. and Bartalis, Z., 2007, Temporal and spatial variability of the beginning and end of daily spring freeze/thaw cycles derived from scatterometer data. Remote Sensing of Environment, 106, pp. 360-374.

Colbeck, S.C. 1997. A review of sintering in seasonal snow cover. CRREL Report 97-10 (Hanover, VA: Cold Regions Research and Engineering Laboratory).

Comiso, J., 1999, updated 2007, Bootstrap Sea Ice Concentrations from NIMBUS-7 SMMR and DMSP SSM/I, 1988-2006. Digital media (Boulder, CO: National Snow and Ice Data Center). 
Comiso, J.C. and Gordon, A.L., 1998, Interannual variability in summer sea ice minimum, coastal polynyas and bottom water formation in the Weddell Sea. In Antarctic Sea Ice: Physical Processes, Interactions and Variability, M.O. Jeffries (Ed.), pp. 293-315. Antarctic Research Series 74 (Washington, DC: American Geophysical Union).

DrinkwATER, M.R. 1998, Active microwave remote sensing observations of Weddell Sea ice. In Antarctic Sea Ice: Physical Processes, Interactions and Variability, M.O. Jeffries (Ed.), pp. 187-212. Antarctic Research Series 74 (Washington, DC: American Geophysical Union).

Drinkwater, M.R. and Liu, X., 2000, Seasonal to interannual variability in Antarctic sea-ice surface melt. IEEE Transactions on Geoscience and Remote Sensing, 38, pp. 1827-1842.

EICKEN, H., 1998, Factors determining microstructure, salinity and stable-isotope composition of Antarctic sea ice: Deriving modes and rates of ice growth in the Weddell Sea. In Antarctic Sea Ice: Physical Processes, Interactions and Variability, M.O. Jeffries (Ed.), pp. 89-122. Antarctic Research Series 74 (Washington, DC: American Geophysical Union).

Eppler, D.T., Farmer, L.D., Lohanick, A.W., Anderson, M.R., Cavalieri, D.J., Comiso, J., Gloersen, P., Garrity, C., Grenfell, T.C., Hallikainen, M., Maslanik, J.A., Mätzler, C., Melloh, R.A., Rubinstein, I. and Swift, C.T., 1992. Passive microwave signatures of sea ice. In Microwave Remote Sensing of Sea Ice, F.D. Carsey (Ed.), pp. 47-71. Geophysical Monograph 68 (Washington, DC: American Geophysical Union).

Ezraty, R. and Piolle, J.F., 2001, SeaWinds on QuickSCAT polar sea ice grids. Technical report, IFREMER/CERSAT CONVECTION report no. 5, V1.1 (Brussels: European Commission).

Fritsen, C.H., Adams, E.E., McKay, C.P. and Priscu, J.C., 1998, Permanent ice covers of the McMurdo Dry Valley Lakes, Antarctica: liquid water content. In Ecosystem Dynamics in a Polar Desert: The McMurdo Dry Valleys, Antarctica, J.C. Priscu (Ed.), pp. 269-280. Antarctic Research Series 72 (Washington, DC: American Geophysical Union).

Gloersen, P., Campbell, W.J., Cavalieri, D.J., Comiso, J.C., Parkinson, C.L. and Zwally, H.J., 1992, Arctic and Antarctic Sea Ice, 1978-1987: Satellite Passive-Microwave Observations and Analysis. NASA SP-511 (Washington, DC: National Aeronautics and Space Administration)

HAAs, C., 2001, The seasonal cycle of ERS scatterometer signatures over perennial Antarctic sea ice and associated surface ice properties and processes. Annals of Glaciology, 33, pp. 69-73.

Haas, C., Nicolaus, M., Willmes, S., Worby, A. and Flinspach, D., 2008, Sea ice and snow thickness and physical properties of an ice floe in the western Weddell Sea and their changes during spring warming. Deep-Sea Research II, 55, pp. 963-974.

Haas, C., Thomas, D.N. and Bareiss, J., 2001, Surface properties and processes of perennial Antarctic sea ice in summer. Journal of Glaciology, 47, pp. 613-625.

Hellmer, H.H., Haas, C., Dieckmann, G.S. and Schroeder, M., 2006, Sea ice feedbacks observed in western Weddell Sea. EOS Transactions, 87, pp. 173-184.

Hellmer, H.H., Schröder, M., Haas, C., Dieckmann, G.S. and Spindler, M., 2008, The ISPOL drift experiment. Deep-Sea Research II, 55, pp. 913-917.

Howell, S.E.L., Tivy, A., Yackel, J.J. and Scharien, R.K., 2006, Application of a SeaWinds/ QuikSCAT sea ice melt algorithm for assessing melt dynamics in the Canadian Arctic Archipelago. Journal of Geophysical Research, 111, doi: 10.1029/2005JC003193.

Jeffries, M.O., Shaw, R.A., Morris, K., Veazey, A.L. and Krouse, H.R., 1994, Crystal structure, stable isotopes $\delta 18 \mathrm{O}$, and development of sea ice in the Ross, Amundsen and Bellingshausen Seas Antarctica. Journal of Geophysical Research, 99, pp. 985-995. 
Jeffries, M.O., Worby, A.P., Morris, K. and Weeks, W.F., 1997, Seasonal variations in the properties and structural composition of sea ice and snow cover in the Bellingshausen and Amundsen Seas, Antarctica. Journal of Glaciology, 43, pp. 138-151.

Kistler, R., Kalnay, E., Collins, W., Saha, S., White, G., Woollen, J., Chelliah, M., Ebisuzaki, W., Kanamitsu, M., Kousky, V., Dool, H., Jenne, R. and Fiorino, M., 2001, The NCEP/NCAR 50-year reanalysis project. Bulletin of the American Meteorological Society, 82, pp. 247-268.

Lange, M.A. and Eicken, H., 1991, Textural characteristics of sea ice and the major mechanisms of ice growth in the Weddell Sea. Annals of Glaciology, 15, pp. 210-215.

Langlois, A., Fisico, T., Barber, D.G. and Papakyriakou, T.N., 2008, Response of snow thermophysical processes to the passage of a polar low-pressure system and its impact on in situ passive microwave radiometry: a case study. Journal of Geophysical Research, 113, doi:10.1029/2007JC004197.

Maksym, T. and Markus, T., 2008, Antarctic sea ice thickness and snow-to-ice conversion from atmospheric reanalysis and passive microwave snow depth. Journal of Geophysical Research, 113, doi:10.1029/2006JC004085.

Markus, T. and CAVAlieri, D.J., 2006, Interannual and regional variability of Southern Ocean snow on sea ice. Annals of Glaciology, 44, pp. 53-57.

Massom, R., Eicken, H., Haas, C., Jeffries, M.O., Drinkwater, M.R., Sturm, M., Worby, A.P., Wu, X., Lytle, V.I., Ushio, S., Morris, K., Reid, P.A., Warren, S.G. and Allison, I., 2001, Snow on Antarctic sea ice. Reviews of Geophysics, 39, pp. 413-445.

Nghiem, S. and Bertoia, C., 2001, Study of multi-polarization C-band backscatter signatures for Arctic Sea ice mapping with future satellite SAR. Canadian Journal of Remote Sensing, 27, pp. 387-402.

Nghiem, S., Kwok, R., Yueh, S.H., Perovich, D.K., Gow, A.J., Hsu, C.C., Ding, K.H., Kong, J.A. and Grenfell, T.C., 1998, Diurnal thermal cycling effects on backscatter of thin sea ice. IEEE Transactions on Geoscience and Remote Sensing, 36, pp. 111-124.

Nghiem, S., Steffen, K., Kwok, R. and Tsai, W.Y., 2001, Detection of snowmelt regions on the Greenland ice sheet using diurnal backscatter change. Journal of Glaciology, 47, pp. 539-547.

Nicolaus, M., Haas, C., Willmes, S. and Bareiss, J., 2006, Differences of snow melting on Arctic and Antarctic sea ice during spring and summer. Annals of Glaciology, 44, pp. 147-153.

Nicolaus, M., Haas, C. and Willmes, S., 2009, Evolution of first- and second-year snow properties on sea ice in the Weddell Sea during spring-summer transition. Journal of Geophysical Research, 114, doi:10.1029/2008JD011227.

Onstott, R.G., 1992, SAR and Scatterometer signatures of sea ice. In Microwave Remote Sensing of Sea Ice, F.D. Carsey (Ed.), pp. 73-104. Geophysical Monograph 68 (Washington, DC: American Geophysical Union).

Simmonds, I. and Keay, K., 2000, Mean southern hemisphere extratropical cyclone behaviour in the 40-year NCEP-NCAR reanalysis. Journal of Climate, 13, pp. 873-885.

Steffen, K., Nghiem, S., Huff, R. and Neumann, G., 2004, The melt anomaly of 2002 on the Greenland Ice Sheet from active and passive microwave satellite observations. Geophysical Research Letters, 31, doi: 10.1029/2004GL020444.

Venegas, S.A. and Drinkwater, M.R., 2001, Sea ice, atmosphere and upper ocean variability in the Weddell Sea, Antarctica. Journal of Geophysical Research, 106, pp. 16747-16765.

Vihma, T., Johansson, M.M. and Launiainen, J., 2009, Radiative and turbulent surface heat fluxes over Antarctic sea ice in early summer. Journal of Geophysical Research, 114(C04019), doi: 10.1029/2008JC004995.

Voss, S., 2002, Synergetische Charakterisierung von Meereis mit SSM/I und Scatterometerdaten. Berichte aus dem Institut für Umweltphysik, 15, Universität Bremen.

Voss, S., Heygster, G. and Ezraty, R., 2003, Improving sea ice type discrimination by the simultaneous use of SSM/I and scatterometer data. Polar Research, 22, pp. 35-42. 
Willmes, S., Bareiss, J., Haas, C. and Nicolaus, M., 2006, The importance of diurnal processes for the seasonal cycle of sea-ice microwave brightness temperatures during early summer in the Weddell Sea. Annals of Glaciology, 44, pp. 297-302.

Willmes, S., Haas, C, Nicolaus, M. and Bareiss, J., 2009, Satellite microwave observations of the interannual variability of snowmelt on sea ice in the Southern Ocean, Journal of Geophysical Research, 114, doi:10.1029/2008JC004919.

Worby, A.P., Geiger, C.A., Paget, M.J., Van Woert, M.L., Ackley, S.F. and DeLiberty, T.L., 2008, Thickness distribution of Antarctic sea ice. Journal of Geophysical Research, 113, doi: 10.1029/2007JC004254.

Zwally, H.J., Comiso, J.C., Parkinson, C.L., Campbell, W.J., Carsey, F.D. and Gloersen, P., 1983, Antarctic Sea Ice, 1973-1976: Satellite Passive-Microwave Observations. NASA SP-459 (Washington, DC: National Aeronautics and Space Administration). 